Volterra went much farther in his later papers. $\mathrm{He}$ found in biological variation an analogue to Hamilton's principle in mechanies, with Maupertuis's principle of least action not far behind. He reduced the fluctuation equations to a Jacobian partial differential equation, and obtained the corresponding integrals. It is unlucky for us biologists that such paths go smoothly for a while, but then soar to heights unclimbable. Prof. Kostitzin's little book, "La biologie mathématique", for which Volterra wrote a preface, and which was reviewed at length in Nature (of June 5, 1937, p. 943), is enough to show the range and the ultimate complexity of the biological problems. Volterra was not the first in this fertile field. He was forestalled, though he did not know it, by Ronald Ross's "Malaria Equations", by some of W. R. Thompson's studies of insect parasitism, and fully and precisely by A. J. Lotka in his "Physical Biology" (1925) and earlier papers. How much Volterra added of his own is not always easy to say, but he toiled over the subject, and enlarged and clarified it.

D'Arcy W. 'Thompson.

VOLTERRA's fundamental ideas have enriched many branches of mathematics. Most of these ideas can be traced back to his earliest papers, and originated in attempts to solve physical and mechanical problems. Though his books, and especially their titles, might suggest that he was primarily a pure mathematician, his thoughts never ceased to be active with problems of the actual world; he was not content with having devised elegant solutions of problems of applied mathematics, until the result had been tested by measurements on models or observations of the natural phenomena concerned. In his work on elasticity, for example, he made many clever experiments on rubber models, and his pupils or colleagues supplemented these experiments by others in which they used the double refraction method to measure internal strain. Again, in discussing heat flow in the earth, he applied his calculations to the St. Gothard tunnel, and pointed out the practical importance of the theory in tunnel boring. A paper he wrote on the Hall effect was followed by similar observations to test the influence of a magnetic field on the resistance of a metal plate.

Among his most important work was that on integral equations with variable limits, which origin. ated in 1884 from a problem in electrostatics. $\mathrm{He}$ pointed out the analogy with limiting systems of algebraic equations, and in $\mathbf{1 8 9 6}$ developed an elegant solution in terms of iterated kernels. Later he applied his methods to multiple integrals and partial differ. ential equations.

So early as 1887 Volterra introduced the conceptions of 'functions of lines' (or rather curves) and functionals, and in later years developed a calculus of functionals that proved to be of great value in treating integrodifferential equations, such as arose in his theory of 'hereditary' phenomena in physics and biology.

Volterra also showed how to apply Green's theorem in $n$ dimensions to extend Riemann's method of characteristics so that it could be applied to solve boundary problems for linear hyperbolic partial differential equations in $n$ independent variables. In particular, he discussed the cylindrical wave equation, and found the appropriate analogue of Kirchhoff's theorem on wave motion. The idea was also modified to suit systems of equations that occurred in his researches on wave motion in elastic media, and to parabolic equations. He constructed a theory of the differential and integral calculus of substitutions in connexion with the theory of ordinary linear differential equations, and showed that Fuchs's results could be interpreted as an extension of Cauchy's theory of residues.

S. Chapman.

\section{Miss Bertha Porter}

THE gifts of mind and character which, though they may fall short of brilliance, ensure that the holder, unless met by too adverse a fate, will presently find an opportunity for free development and fruitfulness, should be given high rank in a hierarchy of service. Amongst such souls Bertha Porter may be assigned a place.

Born at the end of the early Victorian period to the home of a successful architect in whose house in Russell Square many highly cultured men and women might be met, Bertha Porter early showed a keen interest in knowledge as such, and, after her short school-time at Bedford College was over, pursued this and that with diligence. This mental alertness, combined with methodical habits and selfdiscipline, soon made her serviceable, so that the student of psychical research was in her debt before she contributed to the building up of the "Dictionary of National Biography".

University College was so near Bertha Porter's home that the eager student was quick to eatch the scent of a new trail there, and before long she was swept in, this time finally, to furnish the Egyptological atelier with a labour-saving appliance. Erman in Germany and Griffith in England, aware that for continuity of study the student of their day greatly needed a survey of past research, had perceived Miss Porter's qualifications for bibliographical work. A brief visit to the University of Göttingen had provided her at least with valuable contacts.

After five and twenty years of exact and patient research, Miss Porter had almost brought her labours to the point of publication when it became plain that further progress lay where she would no longer feel at ease. Other women were enlisted to aid her (1924), and gradually replaced her failing energy. But so solidly and accurately had the foundations been laid that the six volumes now published (out of eight or nine) are confessedly almost above criticism. "Porter and Moss" (or, to give the work its proper title, "Topographical Bibliography of Ancient Egyptian Hieroglyphic Texts, Reliefs, and Paintings") is now a household word in Egyptology.

Ten years in bed, after so many at the desk, were cheerfully met with the same patience and oldfashioned humour. Through life Miss Porter had kept to a quaint Victorian dress, as if in quiet assurance that that era needed no apology. 